\title{
Construction Safety Culture and Promotion, Conceptual approach based on the Labor Law of Pakistan
}

\author{
Syed Faraz Jafri ${ }^{1}$ \\ ${ }^{I}$ (Department of Civil Engineering/Sir Syed University of Engineering and Technology, Karachi, Pakistan)
}

\begin{abstract}
The aspect of safety is taken on low priority basis during the execution of projects in Pakistan. Metropolitan cities of Pakistan are well developed by mega projects but safety of labors within construction is not encountered. This predominantly associated with the loss of lives with the decreasing mortality and social value. Negligence of safety standards correspond to the severe and serious injuries. Keeping in view the gravity of issue, the focusing parameter is the use of modernized equipments during construction. As per the statistics, personal safety of deputed workers is less than $40 \%$. The system will be more susceptible by provoking the deployment of policy regulations and awareness programs with implementation procedures governed by functionary bodies. The ultimate goal of research study entices with the sorting of expert labor with their signified requirements. The key controlling features resemble with the locale of labor law, safety development programs and instrumental knowledge.
\end{abstract}

Keywords - Safety, Construction, Policy, Equipment, Labor

\section{CONSTRUCTION INCIDENTS AND LACK OF TRAININGS -AN OVERVIEW}

Construction accidents are entirely dependent on the improper training of labors. Researchers have shown that in many sites no skilled development plan exist in Pakistan. Negligence of safety standards will absolutely result in the form of disasters and loss of precious human life. According to a study, most common types of accidents that occur to specific job, investigation has shown that carpenters have more finger injuries compared to masons [1]. During execution of construction work labors faced different types of accidental issues including falls, scaffolding, electrical related matters, operating equipments or machineries, welding and explosion accidents etc [2]. All of these are equally hazardous and deadly, and each of these can be avoided through effective safety trainings and measures.

\section{IMPLICATIONS FOR THE CITY OF KARACHI AND DEPENDENT AREAS}

Karachi is the capital economical hub of Pakistan, for getting employment, education and medical facilities peoples migrated all around the Pakistan to Karachi. Many of them getting employment related to construction work. Construction companies getting benefits of this unemployment ratio and hire cheap unskilled labor on daily wages to perform the job, this might cause to the increased number of site accidents [3]. Many contactors do have the safety policy, on paper but in practice there is no check and balance of safety constraint. Unemployed labor putting themselves in danger during execution of construction projects and learn from their own mistakes. Also construction equipments manufacturers have a responsibility to design and maintain safe products for use at the work site. This responsibility includes preventing the use of defective or unreasonably dangerous products, which include: scaffolding, power tools, cranes, woodworking tools, ladders, winches, trucks, tractors, bulldozers, forklifts etc [4]. When a construction site accident occurs, the owners, architects, insurance companies and manufacturers of equipment can be held responsible for inadequate safety provisions. For the detailed feature enhancement, the situation is clearly defined in the pictorial views as follows.

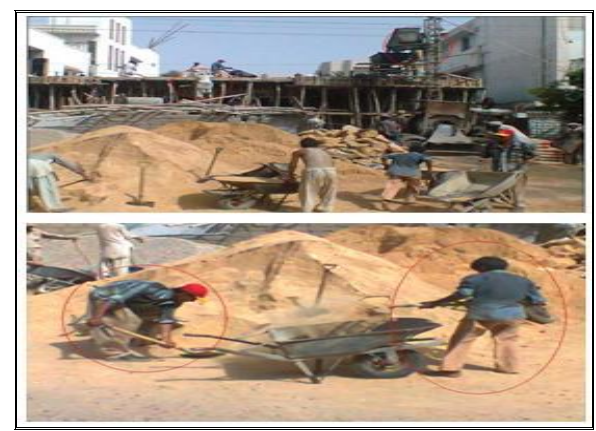

Fig. 1. Unsafe Working Environment (implemented procedures and lack of advanced equipments) [5] 
III.

OBJECTIVES OF THE STUDY

The major objective of this research is to minimize the root cause of accidents, by introducing step to step program for the successful accomplishment of construction site. The general contractor and all subcontractors are required to provide a reasonably safe site, to warn of hazards inherent in the site and work, to hire careful employees, to coordinate job safety and to supervise compliance with safety specifications. The idea and concept should be transformed to the workers and users with the provision of full specifications in the form of booklet and training.

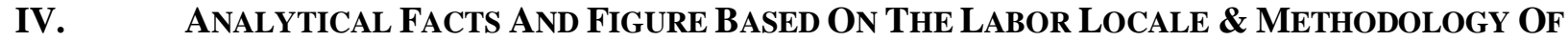 THE RESEARCH STUDY}

A brief questionnaire was designed by taking the help form different questions. In the similar fashion, numbers of targeted sites are visited in Karachi with the stringent observation that labors are having associated with the number of problems and these problems are directly engaged with the inadequate construction safety process. The picture is quite clear from the analysis below:

Table 1. Designed questionnaire with assigned code.

\begin{tabular}{|c|l|}
\hline $\begin{array}{c}\text { Question } \\
\text { Code }\end{array}$ & \multicolumn{1}{|c|}{ Question } \\
\hline A & How many hours you work daily? \\
\hline B & Is this income sufficient to support your dependents? \\
\hline C & Have you aware about safety in construction? \\
\hline D & $\begin{array}{l}\text { Do you get any safety training to work in } \\
\text { construction site? }\end{array}$ \\
\hline E & $\begin{array}{l}\text { Have you ever been injured during construction } \\
\text { work? }\end{array}$ \\
\hline F & $\begin{array}{l}\text { Have you get any compensation against your injury } \\
\text { from the contractor or owner? }\end{array}$ \\
\hline G & $\begin{array}{l}\text { Have you ever been refuse to work, because you } \\
\text { think you are putting yourself in danger? }\end{array}$ \\
\hline H & $\begin{array}{l}\text { If you will not get work on daily basis for 2 or 3 } \\
\text { days, will you ready to work any type of } \\
\text { construction site or nature of work and ignore your } \\
\text { personal safety? }\end{array}$ \\
\hline
\end{tabular}

Each question is assigned with a separate code for the effective formulation in graphical representation; data is then collected and represented as follows. As per the question code C, D and E more than $80 \%$ answers are imparting to the unsafe construction safety procedures. It is quite evident from the analytical facts that effective designing of policy with predefined rules for the labor locality is mandatory and it is only possible with the introduction safety culture in the environment.

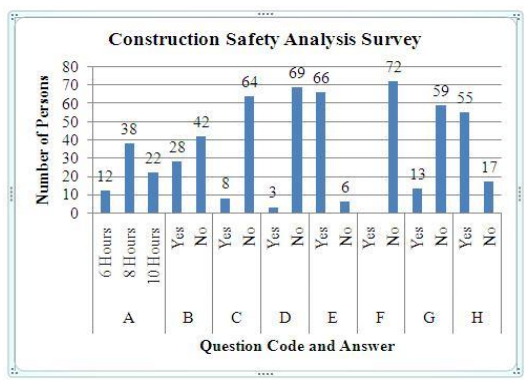

Fig. 2. Construction Safety Analysis Survey Results

\section{Causes And Parental ApProaches To Construction Site ACCidents}

Uncontrolled, unplanned and undesirable incident might not be necessarily result in an injury is term as an accident [4]. All incidents regardless of the damage or loss and nature should be concern, because it may cause prefigure future accidents. An accident does not happen without cause, many accidents are caused by either unsafe act or unsafe conditions or both [6]. In the same way, number of entities is discussed below that are the root cause and giving the solutions in their own as well.

\subsection{Safety Factor Avoidance}

According to the respective research, around $90 \%$ labors agreed they are injured due to negligence of safety parameters. Not only that, $70 \%$ workers are injured due to the unskilled performance and this again correspond to the provision of safety trainings to concerned labors. During the survey, several pictorial views 
are to be taken for the clear justification. The system is also dependent by the improper handling of equipments by labors.

\subsection{Unemployment Ratio}

It is also one of the important factor and proved form the collected data that many construction workers are unemployed (or working on just contract basis) and they are agreed to work without considering safety standards. The whole family is entirely based on that particular labor and they are willing to do extra work in order to get extra beneficial money. In some cases, children of the labors also engaged with that work on daily wages, which is against the Labor Law of Pakistan [7] and also against the Human Rights.

\subsection{Imposition of Extra Working hours to get Extra benefit}

The working hours for desired and particular group of labors are not predefined, with the extra consumed time at site given by workers jobsite accidents increased. Referring to figure 1, the year of 1999 revealed that the most accidents occurred when a worker stayed on the jobsite for more than forty hours per week [8]. Accidents and injuries affecting workers in developing countries are more, because they are the wage earner of their families and their pay scale is low as compare to developed countries. For the fulfillment of their family needs they work more than forty hours per week and neglect the safety polices.

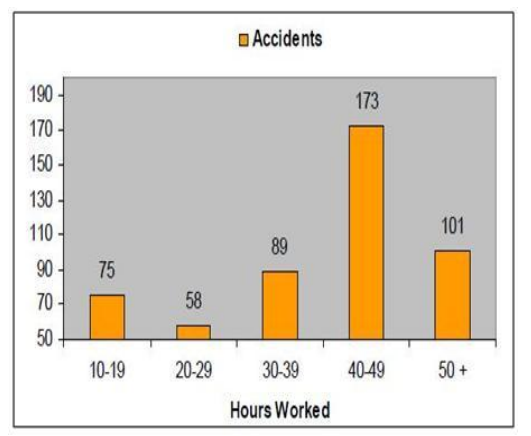

Fig. 3. (EU Construction accidents by hours worked in 1999) [9]

\subsection{Specific Domain for Specific Labors}

As per the statistical data, $60 \%$ of the labors are owned to the specific type of working strategy and transformed to its expertise. The domain of that particular labor is set and the person tries to entrapped with this domain and eventually unskilled in other areas.

\subsection{Age Factor}

The nature of work in our case is independent from this factor. The whole family of the labor is associated is concerned with the specific project due to excessive needs and requirements, policy is not coupled with these issues.

\subsection{Indirect Cost ascertain by the Construction Incident}

When accident occurs in construction site, it has many adverse effects on labor and as well construction site. Indirectly it may involve:

- Disappointment of other workers

- Initiation of low productivity

- Extra imposition of time due to investigation

- Repair and maintenance

- Damage of equipment etc

\section{POLiCy DePloyment AND InSTRUMental Usage}

For the successful accomplishment of any construction project, adequate planning and management of safety ensuring policies should be adopted. All personal safety equipment and signs should be kept available for the use of the persons employed on the site and worker are not allowed to enter the site until they wear protection equipments [10]. The policy makers should stumble upon the basics of Labor Law. These include orientation of safety training programs, introducing permit/licensing for operating construction machineries, increasing literacy to work on construction site. 


\section{VII.}

CONCLUSION AND RECOMMENDATIONS

Construction safety is preamble with several basic facts but they are transformed to the adverse perceived contributions by their avoidance. As the study correlates with ideological items including negligence of labor law, improper working exposure, unsafe construction site etc, all allied with the documented, strategic and sound planning of the existing system. Updating of the existing system is the burning issue because presently the things are taken at the documented level but not the implementation level. In this contrary situation, Education and Enforcement both are part and parcel important at separate stages. Education with ground realities of all type of stakeholders should be signified. Experts, Practitioners and Foreigners should play important role in the effective training sessions. Determinate rules should prefer for each class of stakeholder and they should be monitored at different stages of construction. Not only that, for the avoiding maneuvers, penalty should be imposed to the respective person. New and technology should be introduced to the existing system, it tends to the long term proposal but it should started at small scale like the housing schemes etc. For any construction industry, manpower should be strong enough in order to meet the challenges and demand of intact network.

\section{REFERENCES}

[1] Helander, M. G. (1991). "Safety hazards and motivation for safe work in the construction industry." Int. J. Industrial Ergonomics, London, 8(4), 205-223.

[2] Farooqui, R.U., Ahmed, S.M., and Panthi, K. (2007). "Developing Safety Culture in Pakistan Construction Industry - An Assessment of Perceptions and Practices among Construction Contractors".

[3] Rizwan U. Farooqui, Farrukh Arif and S.F.A. Rafeeqi (August 2008) (Safety Performance in Construction Industry of Pakistan, First International Conference on Construction in Developing Countries (ICCIDC-I). Advancing and Integrating Construction Education, Research \& Practice" August 4-5, 2008, Karachi, Pakistan).

[4] Hinze, Jimmie W. (1998), Co-author Tung Au (1998) Project Management for Construction, Fundamental Concepts for Owners, Engineers, Architects and Builders Construction Safety, Prentice-Hall, 1997.

[5] Azizabad, Block 2, Karachi, Pakistan, Private Construction (28th May 2012)

[6] Ridley, J. (1986) Safety at Work, 2nd Edition. London: Butterworth Ltd.

[7] Government of Pakistan (Labor Policy 2010) Construction Labor Law (Clause 25, 2010).

[8] Scott W. Kramer, Ph.D. and Jack R. Byrd (Department of Building Science, Auburn University) - (Comparative Study of Construction Safety. OSHA in the United States versus EASHW in the European Union 2007) pp. 10 (Proceedings published by: RICS 12 Great George Street, London SW1P 3 AD United Kingdom.

[9] EU construction accidents by hours worked. (EASHW, European Social Statistics, 2004, pg. 166).

[10] Scott W. Kramer, Ph.D. and Jack R. Byrd (Department of Building Science, Auburn University) - (Comparative Study of Construction Safety. OSHA in the United States versus EASHW in the European Union 2007) pp. 10 (Proceedings published by: RICS 12 Great George Street, London SW1P 3AD United Kingdom. 